\title{
A CONTRA-REFORMA UNIVERSITÁRIA: UMA UNIVERSIDADE DIFERENTE É POSSÍVEL...
}

\author{
VALDEMir Pires ${ }^{* *}$
}

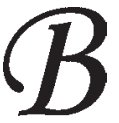

oaventura de Souza Santos, uma vez mais, a partir de sua perspectiva de que nem tudo está dado e perdido, num mundo de uma nota só, faz soar alguns instrumentos que lembram aos de fraca memória o quanto a boa música do pensamento criativo, democrático e emancipatório é viva, boa e faz falta, muita falta. Em $A$ universidade do século XXI: para uma reforma democrática e emancipatória da universidade, recém-publicado pela Cortez (São Paulo, 2004), faz uma consistente análise dos acontecimentos que, nos últimos dez anos, agravaram a crise da universidade, tão bem diagnosticada por ele mesmo em Pelas mãos de Alice: o social e o político na pós-modernidade (São Paulo: Cortez, 1995). Ao invés de ceder à tentação do procedimento, nocivo mas muito encontradiço, de listar e malhar fatos e acontecimentos gerados pela globalização e pelo neoliberalismo (esses dois malvados tão resistentes e perseverantes...), o autor vai muito além, discutindo diretrizes para o que, no título do livro, aparece como "reforma democrática e emancipatória”, mas que nesta resenha opta-se por definir como uma contra-reforma criativa, democrática e emancipatória, para que fique bem situada no contexto da discussão em curso, no Brasil, sobre a reforma do ensino superior (que é mais ampla que a reforma universitária, como o próprio Boaventura alerta).

Souza Santos avalia que a crise tríplice (crise de hegemonia, crise de legitimidade e crise institucional) enfrentada há muito tempo pela universidade pública foi agravada, na última década, i) pela sua deliberada descapitalização (na esteira do recuo do Estado do Bem-Estar So-

Resenha do livro de Boaventura de Souza Santos, A universidade do Século XXI: para uma reforma democrática e emancipatória (São Paulo: Cortez, 2004. 120p.).

** Economista, doutor em Educação e professor da Universidade Metodista de Piracicaba (UNIMEP).E-mail: vapires@terra.com.br

Educ. Soc., Campinas, vol. 25, n. 88, p. 1071-1075, Especial - Out. 2004 
A contra-reforma universitária: uma universidade diferente é possível...

cial); ii) pela conversão das novas tecnologias da informação e da comunicação em instrumentos pedagógicos que prescindem da co-presença e questionam de um modo ainda não compreendido a relação tradicional entre professor-aluno; iii) pela tendência de transnacionalização do ensino superior (tomado como mercadoria como qualquer outra); e iv) pelo fato de os caminhos escolhidos para enfrentar a crise estarem passando predominantemente, senão quase que exclusivamente, pelo enfrentamento do seu aspecto institucional, que é o mais visível, porém o menos promissor para oferecer respostas às inúmeras e complexas questóes que a crise envolve.

Foi no processo de produção de respostas à crescente perda de capacidade de responder aos inúmeros - e muitas vezes contraditórios - objetivos que governo e sociedade vêm lhe atribuindo, que os agentes do interior da universidade e os demais atores políticos com ela envolvidos já a reformaram sem fazer alarde, sob denúncia dos prejudicados, dos descontentes e dos segmentos sociais alertas contra os malefícios do pensamento único.

No Brasil, falar de reforma universitária é não ter percebido que ela já ocorreu, tendo início com a implantação da nova Lei de Diretrizes e Bases da Educação Nacional (LDB), prosseguindo com o veto aos itens do Plano Nacional de Educação que demandavam recursos adicionais e consolidando-se pela completa modificação do sistema de ensino superior em razão do grande peso relativo do setor privado na oferta de vagas. Se ainda não chegou o momento de tentar ressuscitar a universidade pública, é certo que já é chegada a hora de fazer algo para evitar seus últimos suspiros.

Trata-se, pois, de encetar a contra-reforma universitária para reverter os estragos já produzidos pela reforma universitária, que já passou por vários aniversários, mas ainda não recebeu batismo nem certidão de nascimento, talvez porque seus pais não tenham tido a coragem de assumi-la publicamente.

É, na verdade, sobre essa contra-reforma necessária que as luzes de Souza Santos se lançam com poder esclarecedor. Ele argumenta que é preciso lidar de frente com a dimensão da legitimidade da crise para produzir enfrentamentos eficazes contra ela. Foi-se o tempo em que a universidade se legitimava simplesmente por ser o local sagrado da produção do conhecimento, pólo irradiador do avanço da razão, da verda- 
de, da ciência. Diante de novos e mal definidos desafios, a sociedade pressiona a universidade para que a ajude a enfrentá-los e com rapidez maior do que lhe tem sido habitual. Sem atender a esses apelos, não deverá o mundo universitário esperar mais do que já tem; pelo contrário, a fonte de financiamento continuará secando, gerando crises institucionais, sem solução à vista.

Para reconquistar a legitimidade perdida, a universidade pública terá, segundo Souza Santos, que reforçar sua responsabilidade social, melhor definir sua relação com a indústria (não se limitando a definir suas prioridades em função de fontes de financiamento alternativas), estabelecer um relacionamento sinergético com a escola pública, melhorar as condiçôes de acesso, dar maior atenção à extensão, implementar a pesquisa-ação e adotar a perspectiva da ecologia de saberes (saber dialogar com conhecimentos que, rotulados de não-científicos, foram banidos para fora dos muros da universidade). Além disso, no campo da crise institucional, tem que aprender a atuar em rede, adotar procedimentos participativos de avaliação e rever os mecanismos internos e externos de democratização.

Fica claro, o tempo todo, no rápido e instigante livro, que se trata de "enfrentar o novo com o novo", começando por uma nova e mais complexa definição da crise - "é necessário revisitar os conceitos de crise de hegemonia e de legitimidade" (p. 62) - e passando por um posicionamento: i) de que nem todas as mudanças negativas que estão ocorrendo na universidade têm fundo mercantil; e ii) de que a globalização oferece, sim, pelo menos interstícios para um tipo de relacionamento interuniversitário que vá além da transnacionalização do rico e novo espaço de valorização que se abre ao capital disposto a produzir no mercado de ensino superior. Sem sair da cômoda posição concedida por uma hegemonia e por uma legitimidade gratuitamente concedidas (depois de obtida esta a duras penas pelas primeiras instituições universitárias), as universidades públicas maduras correm o risco de "cair de podres": ou percebem que improvisados rearranjos institucionais em defesa de uma suposta autonomia são enganosos e passageiros ou perderão terreno todos os dias para novas estruturas de governança corporativa, legitimadas por regras de mercado, que vão rapidamente ganhando terreno nos sistemas mistos (público e privado) de oferta de ensino superior. 
A contra-reforma universitária: uma universidade diferente é possível...

E quanto às universidades privadas? Ah, sim, é preciso lembrar delas no caso brasileiro. E não apenas para dizer que devem ser reguladas. Nesse setor:

Alguns produtores de serviços são muito antigos, enquanto outros, a maioria, surgiram nas duas últimas décadas. Alguns têm objetivos cooperativos ou solidários, não lucrativos, enquanto a esmagadora maioria tem fins lucrativos. Algumas são verdadeiras universidades, a maioria não o é e, nos casos piores, são meras fabriquetas de diplomas-lixo. (p. 106-107)

É preciso, nesse campo, separar o joio do trigo, já que é possível distinguir um de outro. E botar lixo na lixeira e milho na canjiqueira. Do contrário, o órgão normatizador e fiscalizador torna-se um averiguador inconveniente, inconstante e autoritário, mais criando barreiras e constrangimentos a quem faz o que deve ser feito, do que usando o seu poder de polícia para evitar a atuação livre e desimpedida de oportunistas.

Não basta, no tocante à qualidade, no Brasil, dizer, como o MEC, em documento de agosto de $2004^{1}$ que:

O setor público do sistema de ensino superior no país apresenta elevado grau de qualidade, a despeito das imensas dificuldades financeiras que vem atravessando há alguns anos. Avaliaçôes de suas atividades de ensino, pesquisa e extensão têm demonstrado a média elevada que o sistema alcança e registrado a existência de unidades de excelência, comparáveis às melhores instituições do mundo. Apesar da precariedade e da irregularidade do financiamento, as instituições públicas podem ser apontadas, em linhas gerais, como o marco de qualidade acadêmica a ser tomado como referência.

Tão heterogêneo, o subsistema público de ensino superior não pode ser apontado com segurança como parâmetro exclusivo para modelar a qualidade. Há nele instituiçôes de qualidade duvidosa, assim como no setor privado. Algumas até deveriam encerrar atividades, assim como as "caça-níqueis" tão criticadas. Fechar os olhos a isso, assim como não captar, no interior do subsistema privado, elementos de qualidade que ofuscam grande quantidade de universidades públicas, é não saber ou não querer trabalhar com a realidade, escamoteando-a por razôes corporativistas ou de preconceito. Por mais que se diga que nas recentes avaliaçóes de desempenho dos alunos ("Provão") os egressos das

1074 Educ. Soc., Campinas, vol. 25, n. 88, p. 1071-1075, Especial - Out. 2004

Disponível em <http://www.cedes.unicamp.br> 
universidades públicas em geral tiveram melhor desempenho que os alunos das escolas privadas, é preciso considerar que estando em escolas com estruturas e professores de mesma qualidade (baixa ou alta), alunos mais bem preparados pelo sistema de ensino pré-universitário, estudando em período integral, devem, com maior probabilidade, atingir melhor desempenho que alunos vindos do precário ensino público e, adicionalmente, cursando a faculdade em período noturno, em salas de aula superlotadas.

A legitimação do subsistema público de ensino superior, no Brasil, não ocorrerá simplesmente negando legitimidade ao subsistema privado, ao qual as portas foram escancaradas nos últimos anos para cumprir funções que o governo excluiu de suas prioridades. Muito pelo contrário, apesar de cobrar mensalidades altas para o poder aquisitivo da grande maioria da população, este setor tem proporcionado maior facilidade de acesso (muitas vezes à revelia da qualidade de ensino, é verdade, em muitos casos), já que amplia vagas enquanto o setor público não o faz na magnitude necessária. Nesse tocante, há que se lançar um olhar para a história da constituição da universidade brasileira: sua perda de legitimidade não tem crescido somente por causa dos fatores mencionados por Souza Santos; sempre houve, adicionalmente, ingredientes de privatização do espaço e dos recursos públicos em seu interior, a exemplo do que aconteceu, de resto, em todas as áreas de atuação governamental. Assim, desprivatizar a universidade brasileira é uma tarefa que ainda se coloca. E chamar a atenção para esse fato, além de outros de igual importância para compreensão da especificidade do caso da educação superior no Brasil, tem sido tarefa a que vêm se dedicando muitos estudiosos brasileiros, tão destacadamente como Marilena Chaui, única citada (não sem merecer) por Souza Santos. ${ }^{2}$

\section{Notas}

1. Ministério da Educação, Reafirmando princípios e consolidando diretrizes da reforma da educação superior, 02 de agosto de 2004.

2. Fica o registro, mas não o protesto, pois o tamanho do deslize é muito pequeno em comparação com o tamanho da contribuição do autor, de quem se pode esperar ainda mais, para uma possível universidade diferente, tanto do subsistema privado como do subsistema público brasileiros atuais. 